\title{
Polymerization of Ring-Substituted Phenylalanine $N$-Carboxyanhydride by Poly(2-vinylpyridine)
}

\author{
Yukio Imanishi, Yoshio Amimoto, Yutaka Hashimoto, \\ and Toshinobu Higashimura \\ Department of Polymer Chemistry, Faculty of Engineering, \\ Kyoto University, Kyoto, Japan.
}

(Received May 27, 1976)

\begin{abstract}
Polymerizations of a series of phenylalanine NCA's carrying various ring substituents, such as $p-\mathrm{CH}_{3} \mathrm{O}, p-\mathrm{H}, p-\mathrm{NO}_{2}$, and $m-\mathrm{NO}_{2}$, initiated by poly(2-vinylpyridine) were investigated in different solvents, such as dimethylformamide, nitrobenzene, methyl benzoate, and acetophenone; the polymerization rates were compared with those induced by $\alpha$-picoline. The binding constants of the $\alpha$-amino acid NCA's for different initiators were also determined. It was concluded that in methyl benzoate or acetophenone poly(2-vinylpyridine) is particularly effective in the polymerization of electron-accepting NCA because the electron-donating polymer binds NCA through hydrogen bonding as well as through a charge-transfer interaction. In nitrobenzene only the hydrogen bonding between the polymer and the NCA's was involved in the accelerated polymerization by poly(2-vinylpyridine). In dimethylformamide no interactions were operating between the polymer and the NCA's, and consequently the polymerization by poly(2-vinylpyridine) which is a weaker base than $\alpha$-picoline was slower. These findings suggest the possibility of substrate-selective polymerization using a polymer initiator with a suitable choice of solvent.

KEY WORDS Ring-Substituted Phenylalanine NCA / Polymer Initiator / Solvent / Hydrogen Bond / Charge-Transfer Interaction / Selectivity /
\end{abstract}

The efficiency and the specificity of enzyme catalysis have been considered to come partly from the complexation of a substrate by the enzyme. ${ }^{1}$ The complexation takes place through secondary valence forces such as hydrogen bonding, charge-transfer interaction, hydrophobic interaction, and electrostatic interaction. ${ }^{2}$ In order to transplant features of the enzyme into a synthetic catalyst, the enzyme catalysis has been investigated by using simplified model systems. ${ }^{3}$ These models have usually been macromolecular compounds, which possess sites for substrate binding as well as sites for catalytic action. The present authors have investigated the polymerization of $\alpha$-amino acid $N$-carboxyanhydride (NCA) initiated by polymeric amines. The binding of NCA by the polymeric amine through the hydrogen bonding resulted in a sizable increase of the polymerization rate ${ }^{4-7}$
The charge-transfer interaction between the polymeric amine and NCA was also found to affect the polymerization rate. ${ }^{8}$ Furthermore, it has been suggested that the hydrogen bonding and the charge-transfer interaction affect the polymerization rate concurrently. ${ }^{9}$

A combination of different types of interactions, such as hydrogen bonding and charge-transfer interaction, could lead to a more efficient and more selective catalyst, as in the case of enzymes. To this end poly(2-vinylpyridine) was chosen as an initiator for the NCA polymerization. The pyridyl group, a tertiary amine which initiates the polymerization of $\mathrm{NCA}^{10}{ }^{10}$ is a hydrogen-bond acceptor and an electron donor. Therefore poly(2-vinylpyridine) could be an efficient and selective initiator for the polymerization of NCA, which carries an active hydrogen and an electron-accepting substituent. In the 
present investigation, the polymerizations of ring-substituted phenylalanine NCA's were investigated in various solvents. The effects of the ring substituent and the solvent on the hydrogen bonding and the charge-transfer interaction between the initiator and the NCA, and consequently on the polymerization rate, were investigated.

\section{EXPERIMENTAL}

\section{Reagents}

NCA. Commercial DL-phenylalanine (Phe) was suspended in tetrahydrofuran (THF) and phosgene was bubbled through to give Phe NCA. This was recrystallized from ethyl acetate, which had been dried over $\mathrm{CaH}_{2}$ and distilled. $p$ Methoxy-DL-phenylalanine $\left(p-\mathrm{CH}_{3} \mathrm{OPhe}\right)$ was synthesized from $p$-methoxyaniline by the Meerwein reaction. ${ }^{11} p-\mathrm{CH}_{3} \mathrm{OPhe}$ NCA was synthesized from the amino acid in the same manner as that for Phe NCA, mp $143.8^{\circ} \mathrm{C}$. $m$-NitroDL-phenylalanine $\left(m-\mathrm{NO}_{2} \mathrm{Phe}\right)$ was also synthesized from $m$-nitroaniline by the Meerwein reaction. ${ }^{11} m-\mathrm{NO}_{2}$ Phe NCA was synthesized from the amino acid in the same manner as that for Phe NCA, mp $147.5^{\circ} \mathrm{C}$. $p$-Nitro-DL-phenylalanine $\left(p-\mathrm{NO}_{2} \mathrm{Phe}\right)$ was synthesized ${ }^{8}$ by the hydrolysis of diethyl $p$-nitrobenzylformylaminomalonate, which was obtained from $p$-nitrobenzyl chloride and diethyl formylaminomalonate. $p-\mathrm{NO}_{2}$ Phe NCA was synthesized from the amino acid in the same manner as that for Phe $\mathrm{NCA}, \mathrm{mp} 184-185^{\circ} \mathrm{C}$.

Initiator. Commercial 2-vinylpyridine (2-VP) was distilled in vacuum twice over $\mathrm{CaH}_{2}$, bp $68^{\circ} \mathrm{C}(30 \mathrm{~mm})$. It was polymerized in toluene/ $\mathrm{CCl}_{4}(83: 17 \mathrm{v} / \mathrm{v})$ mixed solvent with AIBN as an initiator in a sealed tube heated at $60^{\circ} \mathrm{C}$ for $48 \mathrm{hr}$. Poly(2-VP), obtained in $65-\%$ yield, was characterized by viscometry and NMR: $[\eta]=0.251$ (methanol, $25^{\circ} \mathrm{C}$ ), $\overline{\mathrm{DP}}_{n}=360^{12}$, fraction of isotactic triad ${ }^{13-15}=0.3$. Commercial $\alpha$-picoline was refluxed over $\mathrm{BaO}$ and distilled twice over $\mathrm{BaO}$, bp $128-129^{\circ} \mathrm{C}$. Sarcosine dimethylamide (SarDMA) was synthesized as reported previously ${ }^{16}$. Polysarcosine dimethylamide [Poly(Sar)DMA] having $\overline{\mathrm{DP}}_{n}=15$ was synthesized by the polymerization of Sar NCA by SarDMA; here the initial molar ratio [Sar NCA]/[SarDMA] was 14.

Solvent. Nitrobenzene was dried with $\mathrm{P}_{2} \mathrm{O}_{5}$ and distilled under vacuum twice over $\mathrm{BaO}$ and once more just before use, bp $60^{\circ} \mathrm{C}(5 \mathrm{~mm})$. Methyl benzoate was washed and distilled under vacuum twice over $\mathrm{CaH}_{2}$, bp $47^{\circ} \mathrm{C}(4.3 \mathrm{~mm})$. Acetophenone was distilled under vacuum twice over $\mathrm{P}_{2} \mathrm{O}_{5}$, bp $67^{\circ} \mathrm{C}(7.8 \mathrm{~mm})$. Dimethylformamide (DMF) was dried with $\mathrm{P}_{2} \mathrm{O}_{5}$ and distilled under vacuum twice, bp $38^{\circ} \mathrm{C}(6.5 \mathrm{~mm})$.

\section{Procedures}

Polymerizations by the tertiary amines such as poly(2-VP) and $\alpha$-picoline, were slow enough to follow with a constant-pressure apparatus as reported by Patchornik, et al. ${ }^{17}$ In this method the carbon dioxide evolved in the polymerizatlon was trapped with benzylamine and titrated with sodium methoxide.

The polymerizations by the secondary amines, such as poly(Sar)DMA and SarDMA, were so fast that the polymerization could be carried out in a constant-volume apparatus as reported by Sisido, et $a{ }^{4}{ }^{4}$ In this method the pressure increase of the carbon dioxide evolved in the polymerization was measured with a manometer.

The equilibrium constant for the hydrogen bonding between NCA and initiator was determined by infrared spectroscopy. The amount of unbound NCA was determined using the IR absorption due to free NH of NCA. ${ }^{18}$ To avoid a substantial polymerization during the IR measurements, the amino end of poly(Sar)DMA was blocked by adding $N$-phenylglycine NCA. ${ }^{4}$ Poly $(2-V P)$ and $\alpha$-picoline were mixed with NCA without modification. A trivial decrease of the NCA concentration due to a slow polymerization had little effect on the IR measurement.

\section{RESULTS}

\section{Contribution of Hydrogen Bonding to the Poly- merization}

The polymerization of Phe NCA using poly(Sar)DMA as an initiator is a fast polymerization which has been shown to be induced by an intramolecular attack of the terminal secondary amino group on the NCA adsorbed on a peptide carbonyl group by hydrogen bonding. ${ }^{19}$ If the polymerization of ring-substituted NCA by 
NCA Polymerization by Polymer

Table I. The rate of polymerization $\left(R_{\mathrm{pi}}\right)^{\mathrm{a}}$ of ring-substituted phenylalanine NCA by sarcosine dimethylamide and polysarcosine dimethylamide $(n=15)$ at $25^{\circ} \mathrm{C}$ in nitrobenzene

\begin{tabular}{|c|c|c|c|c|}
\hline \multirow{2}{*}{ Initiator } & \multicolumn{4}{|c|}{$R_{\mathrm{pi}}, M \mathrm{~min}^{-1}$} \\
\hline & $p$ - $\mathrm{CH}_{3} \mathrm{OPhe} \mathrm{NCA}$ & Phe NCA & $m-\mathrm{NO}_{2} \mathrm{Phe} \mathrm{NCA}$ & $p-\mathrm{NO}_{2} \mathrm{Phe} \mathrm{NCA}$ \\
\hline SarDMA $(n=1)$ & $2.54 \times 10^{-3}$ & $2.55 \times 10^{-3}$ & $\begin{array}{c}9.86 \times 10^{-3} \\
\left(8.25 \times 10^{-3}\right)^{b}\end{array}$ & $\begin{array}{c}4.17 \times 10^{-3} \\
\left(3.43 \times 10^{-3}\right)^{b}\end{array}$ \\
\hline $\operatorname{Poly}(\operatorname{Sar}) \operatorname{DMA}(n=15)$ & $2.19 \times 10^{-2}$ & $2.65 \times 10^{-2}$ & $\begin{array}{l}6.27 \times 10^{-2} \\
\left(5.10 \times 10^{-2}\right)^{b}\end{array}$ & $\begin{array}{l}6.55 \times 10^{-2} \\
\left(6.89 \times 10^{-2}\right)^{b}\end{array}$ \\
\hline$\frac{R_{\mathrm{pi}}(n=15)}{R_{\mathrm{pi}}(n=1)}$ & 8.6 & 10.4 & $\begin{array}{l}6.4 \\
(6.2)\end{array}$ & $\begin{array}{l}15.4 \\
(20.1)\end{array}$ \\
\hline
\end{tabular}

[NCA], $5.0 \times 10^{-2} M$; [Amine], $2.5 \times 10^{-3} M$.

b Experiments in duplicate.

poly(Sar)DMA is compared with that by SarDMA, the effect of binding the NCA through hydrogen bonding can be assessed. The effect of the ring substituent on the hydrogen bonding can be determined at the same time. The initial rates of the polymerizations $\left(R_{\mathrm{pi}}\right)$ initiated by poly(Sar)DMA and by SarDMA and their ratio were determined for the polymerization in nitrobenzene at $25^{\circ} \mathrm{C}$ and are shown in Table I. The reproducibility of the $R_{\mathrm{pi}}$ ratio was satisfactory. Since the nitrophenylalanine NCA's are very reactive for the polymerization, they were tested for reproducibility. On this basis, the experimental error included in the individual $R_{\mathrm{pi}}$ should be within $20 \%$. This will lead to an experimental error for the $R_{\mathrm{pi}}$ ratio as large as $50 \%$. In view of these considerations, $R_{\mathrm{pi}}$ $(n=15) / R_{\mathrm{pi}}(n=1)$ is nearly constant at about 10 for the polymerizations of Phe NCA, $p-\mathrm{CH}_{3} \mathrm{OPhe}$ $\mathrm{NCA}, p-\mathrm{NO}_{2} \mathrm{Phe} \mathrm{NCA}$, and $m-\mathrm{NO}_{2} \mathrm{Phe} \mathrm{NCA}$. A more important conclusion is that $R_{\mathrm{pi}}$ ratio is not specifically correlated with the nature of the substituents.

The equilibrium constant for hydrogen bond-

Table II. Equilibrium constant $(K)$ for hydrogen bonding between ring-substituted phenylalanine

NCA and polysarcosine dimethylamide $(n=15)$ blocked by $N$-phenylglycine NCA in methylene chloride

\begin{tabular}{lc}
\hline \multicolumn{1}{c}{$\mathrm{NCA}$} & $K, M^{-1}$ \\
\hline$m$ - $\mathrm{NO}_{2}$ Phe NCA & $6.2 \pm 0.7$ \\
Phe NCA & $4.2 \pm 0.2$ \\
$p$ - $\mathrm{CH}_{3} \mathrm{OPhe} \mathrm{NCA}$ & $5.0 \pm 0.6$ \\
\hline
\end{tabular}

ing between the ring-substituted Phe NCA and poly(Sar)DMA was determined in $\mathrm{CH}_{2} \mathrm{Cl}_{2}$, and is shown in Table II. For Phe NCA, $p-\mathrm{CH}_{3} \mathrm{OPhe}$ $\mathrm{NCA}$, and $m-\mathrm{NO}_{2}$ Phe NCA the equilibrium constants were almost the same.

The above experimental results indicate that, in the polymerizations of a series of ring-substituted Phe NCA's using a polymeric initiator which possesses some sites for binding NCA through hydrogen bonding and a terminal catalytic site, the ring substituent does not seriously affect the NCA adsorption or the extent of acceleration.

Contribution of Coupled Hydrogen Bonding and Charge-Transfer Interaction to the Polymerization

Poly(2-VP) is similar to poly(Sar)DMA in that it is a polymeric initiator equipped with both sites for binding NCA through hydrogen bonding and catalytic sites to initiate the polymerizatson. However, the pyridyl groups of poly(2-VP) are electron-donating and these groups may have charge-transfer interactions with an electronaccepting substituent of NCA, which would hardly be expected for poly(Sar)DMA. Hydrogen bonding and charge-transfer interaction may participate simultaneously in the polymerization of ring-substituted Phe NCA initiated by poly(2-VP). These interactions will be influenced by the nature of the solvent as well.

First of all, the polymerization of ring-substituted NCA initiated by poly(2-VP) was carried out in DMF. A time-conversion curve was obtained and a first-order plot with respect to the NCA concentration was drawn. The poly- 
Table III. The rate of polymerization ${ }^{a}$ of ring-substituted phenylalanine NCA by $\alpha$-picoline $\left(R_{\mathrm{p}}\right)$ and poly(2-vinylpyridine) $\left(R_{\mathrm{p}}{ }^{\prime}\right)$ at $35^{\circ} \mathrm{C}$ in dimethylformamide

\begin{tabular}{cccc}
\hline \multicolumn{1}{c}{$\mathrm{NCA}$} & $R_{\mathrm{p}^{\prime}}, M \mathrm{~min}^{-1}$ & $R_{\mathrm{p}}, M \mathrm{~min}^{-1}$ & $R_{\mathrm{p}}{ }^{\prime} / R_{\mathrm{p}}$ \\
\hline$p-\mathrm{NO}_{2}$ Phe NCA & $2.83 \times 10^{-5}$ & $6.71-10.33 \times 10^{-5}$ & $0.27-0.42$ \\
$m-\mathrm{NO}_{2}$ Phe NCA & $2.78 \times 10^{-5}$ & $6.07-8.94 \times 10^{-5}$ & $0.31-0.46$ \\
Phe NCA & $7.70 \times 10^{-6}$ & $2.79 \times 10^{-5}$ & 0.28 \\
$p-\mathrm{CH}_{3} \mathrm{OPhe} \mathrm{NCA}$ & $1.31 \times 10^{-5}$ & $3.29 \times 10^{-5}$ & 0.38
\end{tabular}

a $[\mathrm{NCA}]=0.1 \mathrm{M},[\mathrm{NCA}] /[$ Pyridine $]=1$.

Table IV. The rate of polymerization ${ }^{\text {a }}$ of ring-substituted phenylalanine NCA by $\alpha$-picoline $\left(R_{\mathrm{p}}\right)$ and poly(2-vinylpyridine $)\left(R_{\mathrm{p}}{ }^{\prime}\right)$ at $35^{\circ} \mathrm{C}$ in nitrobenzene

\begin{tabular}{lccc}
\hline \multicolumn{1}{c}{$\mathrm{NCA}$} & $R_{\mathrm{p}}{ }^{\prime}, M \mathrm{~min}^{-1}$ & $R_{\mathrm{p}} \mathrm{b}, M \mathrm{~min}^{-1}$ & $R_{\mathrm{p}^{\prime} / R_{\mathrm{p}}{ }^{\mathrm{b}}}$ \\
\hline$m$-NO ${ }_{2}$ Phe NCA & $2.40 \times 10^{-4}$ & $1.66-2.20 \times 10^{-4}$ & $1.09-1.44$ \\
Phe NCA & $7.65 \times 10^{-5}$ & $3.76-6.53 \times 10^{-5}$ & $1.17-2.03$ \\
$p-\mathrm{NO}_{2}$ Phe NCA & $4.39 \times 10^{-5}$ & $2.35-2.60 \times 10^{-5}$ & $1.69-1.87$ \\
\hline
\end{tabular}

a [NCA], 0.1 M; [NCA]/[Pyridine], 1.

b Maximum and minimum values are given. For the meaning, see the text.

merization rate was determined from the maximum slope in the initial part of the plot. When the polymerization is auto-accelerated, two linear parts were obtained in the first-order plot. In such a cases the maximum and the minimum polymerization rates were determined from each part. The polymerization rates obtained by poly (2-VP) $\left(R_{\mathrm{p}}{ }^{\prime}\right)$ and $\alpha$-picoline $\left(R_{\mathrm{p}}\right)$, and their ratio $\left(R_{\mathrm{p}}{ }^{\prime} / R_{\mathrm{p}}\right)$ were determined and are shown in Table III.

DMF is well-known dipolar aprotic solvent: it is a strong hydrgen-bond acceptor ${ }^{20}$ and interacts with aromatic compounds. ${ }^{21}$ It has been reported that $N, N$-dimethylacetamide, which is similar to DMF in nature, is a stronger hydrogen-bond acceptor than nitrobenzene, methyl benzoate, and acetophenone, although weaker than pyridines. $^{22}$ In methylene chloride $N, N$ dimethylacetamide forms a hydrogen bond with Phe NCA; the equilibrium constant for this has been reported to be $9.4 \pm 0.8 M^{-1}\left(29^{\circ} \mathrm{C}\right)$, which is certainly larger than those presented in Table II. Due to the strong solvating power of DMF, no evidence for the hydrogen bonding between polymeric initiators and Phe NCA was observed in the polymerizations induced by polysarcosine dimethylamide ${ }^{19}$ and copolymers of $N$-vinyl-2-ethylimidazole in $\mathrm{DMF}{ }^{9}$ Using $\mathrm{DMF}$ as solvent does not facilitate the chargetransfer interactions. In our preliminary ex- periment, ${ }^{23}$ we determined the equilibrium constant for the charge-transfer complex between poly(DL- $\left.m-\mathrm{NO}_{2} \mathrm{Phe}\right)$ and $N, N, N^{\prime}, N^{\prime}$-tetramethylp-phenylenediamine. The equilibrium constant determined at $25^{\circ} \mathrm{C}$ using the absorbancy at $490 \mathrm{~nm}$ according to a Benesi-Hildebrand plot was $17.5 \mathrm{M}^{-1}$ in trimethylphosphate but only $2.42 M^{-1}$ in DMF. Therefore, when DMF is used as solvent, neither hydrogen bonding nor charge-transfer interaction occurs between poly(2-VP) and NCA to any significant extent. In this solvent, $R_{\mathrm{p}}{ }^{\prime} / R_{\mathrm{p}}$ was as low as ca. 0.3 for every NCA.

Next, the polymerization of ring-substituted NCA by poly(2-VP) was carried out in nitrobenzene. $R_{\mathrm{p}}{ }^{\prime}$ by poly(2-VP), $R_{\mathrm{p}}$ by $\alpha$-picoline, and their ratio $R_{\mathrm{p}}{ }^{\prime} / R_{\mathrm{p}}$ were determined, and are shown in Table IV. In nitrobenzene, the hydrogen bonding between $N$-acetyl polysarcosine dimethylamide and Phe NCA has been investigated; the equilibrium constant for the hydrogen bonding was determined to be $5 \mathrm{M}^{-1}$ at $29.3^{\circ} \mathrm{C}^{18}$, which is comparable to those presented in Table II. Evidence for the hydrogen bonding between the polymeric initiator and the monomer has been found in the polymerization of Phe NCA initiated by poly $(2-V P)^{7}$. But charge-transfer interactions do not occur between poly(2-VP) and NCA, because nitrobenzene is strongly electron-accepting. The interaction with NCA 
NCA Polymerization by Polymer

Table $\mathbf{V}$. The rate of polymerization of ring-substituted phenylalanine NCA by $\alpha$-picoline $\left(R_{\mathrm{p}}\right)$ and poly(2-vinylpyridine) $\left(R_{\mathrm{p}}{ }^{\prime}\right)$ at $35^{\circ} \mathrm{C}$ in methyl benzoate or acetophenone

\begin{tabular}{|c|c|c|c|}
\hline NCA & $R_{\mathrm{p}}^{\prime}, M \min ^{-1}$ & $R_{\mathrm{p}}, M \min ^{-1}$ & $R_{\mathrm{p}^{\prime}}^{\prime} / R_{\mathrm{p}}$ \\
\hline \multicolumn{4}{|c|}{ Methyl benzoate ${ }^{a}$} \\
\hline$m-\mathrm{NO}_{2} \mathrm{Phe} \mathrm{NCA}$ & $6.20 \times 10^{-5}$ & $1.49-2.34 \times 10^{-5}$ & $2.66-4.15$ \\
\hline Phe NCA & $5.77 \times 10^{-6}$ & $2.35 \times 10^{-6}$ & 2.46 \\
\hline$p-\mathrm{CH}_{3} \mathrm{OPhe} \mathrm{NCA}$ & $3.17 \times 10^{-6}$ & $2.16 \times 10^{-6}$ & 1.47 \\
\hline \multicolumn{4}{|c|}{ Acetophenone ${ }^{b}$} \\
\hline$p-\mathrm{NO}_{2} \mathrm{Phe} \mathrm{NCA}$ & $7.53 \times 10^{-5}$ & $4.81 \times 10^{-5}$ & 1.56 \\
\hline$m-\mathrm{NO}_{2} \mathrm{Ph}$ NCA & $7.69 \times 10^{-5}$ & $2.43 \times 10^{-5}$ & 3.16 \\
\hline Phe NCA & $2.74 \times 10^{-6}$ & $0.88 \times 10^{-5}$ & 3.11 \\
\hline$p-\mathrm{CH}_{3} \mathrm{OPhe} \mathrm{NCA}$ & $1.74 \times 10^{-5}$ & $1.02 \times 10^{-5}$ & 1.70 \\
\hline
\end{tabular}

a $[\mathrm{NCA}], 0.1 M ;[\mathrm{NCA}] /[$ Pyridine $], 1$.

b [NCA], $0.1 M ;[\mathrm{NCA}] /[$ Pyridine], 0.2 .

Table VI. Equilibrium constant $(K)$ for hydrogen bonding between ring-substituted phenylalanine

NCA and $\alpha$-picoline or poly(2-vinylpyridine) in methylene chloride.

\begin{tabular}{lccc}
\hline & $\begin{array}{c}p-\mathrm{CH}_{3} \mathrm{OPh} \\
\mathrm{NCA}\end{array}$ & $\begin{array}{c}\mathrm{Phe} \\
\mathrm{NCA}\end{array}$ & $\begin{array}{c}m-\mathrm{NO}_{2} \mathrm{Phe} \\
\mathrm{NCA}\end{array}$ \\
\hline Poly(2-VP) & $2.0 \pm 0.7$ & $4.0 \pm 0.5$ & $3.8 \pm 0.8$ \\
$\alpha$-Picoline & $6.3 \pm 2.1$ & $4.5 \pm 0.6$ & $6.4 \pm 0.3$ \\
\hline
\end{tabular}

due to hydrogen bonding makes poly(2-VP) a more effective initiator than $\alpha$-picoline, and $R_{\mathrm{p}}{ }^{\prime} / R_{\mathrm{p}}$ was $\mathrm{ca}$. 1.5 regardless of the nature of the ring substituent.

The polymerization of the ring-substituted Phe NCA by poly(2-VP) was carried out in methyl benzoate and acetophenone. $R_{\mathrm{p}}{ }^{\prime}$ by poly $(2-\mathrm{VP})$, $R_{\mathrm{p}}$ by $\alpha$-picoline, and their ratio $R_{\mathrm{p}}^{\prime} / R_{\mathrm{p}}$ were determined and are shown in Table V. Since methyl benzoate and acetophenone are weaker hydrogen-bond accepters than DMF, ${ }^{20}$ hydrogen bonding should exist between the polymeric bases and NCA's in these solvents. In fact, evidence for the hydrogen bonding between poly(2-VP) and Phe NCA in methyl benzoate and acetophenone has been reported. ${ }^{8,9}$ It has also been reported ${ }^{9}$ that in acetophenone poly(2-VP) formed a charge-transfer complex with $p-\mathrm{NO}_{2} \mathrm{Phe} \mathrm{NCA}$ and $o, p$-dinitro-DL-phenylalanine NCA, which resulted in a new absorption maximum at $445-450 \mathrm{~nm}$. Therefore, in acetophenone and methyl benzoate both hydrogen bonding and charge-transfer interaction take place between poly(2-VP) and NCA. Consequen- tly, poly(2-VP) is a more effective initiator than $\alpha$-picoline, and the $R_{\mathrm{p}}{ }^{\prime} / R_{\mathrm{p}}$ ratio varied in the range of $1-4$ according to the nature of the ring substituent of NCA.

The equilibrium constant for hydrogen bonding between poly(2-VP) and the ring-substituted Phe NCA was determined in $\mathrm{CH}_{2} \mathrm{Cl}_{2}$ and is shown in Table VI. $\mathrm{CH}_{2} \mathrm{Cl}_{2}$ is different from those solvents which were employed in the polymerization, and was used for the infrared work because it is most suitable for the ease of measurement and the precise determination of the equilibrium constant. Bamford and Price ${ }^{18}$ also recommended the use of $\mathrm{CH}_{2} \mathrm{Cl}_{2}$ for the infrared work. They compared the equilibrium constants between $\mathrm{N}$-acetyl polysarcosine dimethylamide and Phe NCA in $\mathrm{CH}_{2} \mathrm{Cl}_{2}$ and in nitrobenzene, and found that both values were nearly the same. ${ }^{18}$ Poly(2-VP) is less basic and sterically more hindered than $\alpha$-picoline. So, without any additional effect, poly(2-VP) should form hydrogen bonds with NCA to a lesser extent than $\alpha$-picoline. In actuality, however, poly(2-VP) formed hydrogen bonds with $m-\mathrm{NO}_{2}$ Phe NCA and Phe NCA to almost the same extent as $\alpha$-picoline, while with $p$ $\mathrm{CH}_{3}$ OPhe NCA it formed them to a definitely lesser extent than $\alpha$-picoline.

\section{DISCUSSION}

$\alpha$-Picoline and poly(2-VP) are tertiary amines and should initiate the polymerization of ringsubstituted Phe NCA according to the activated- 


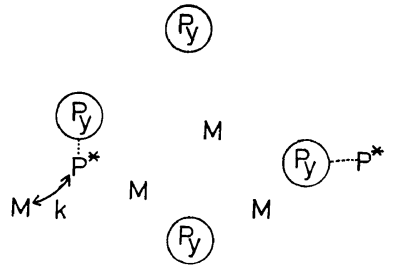

A

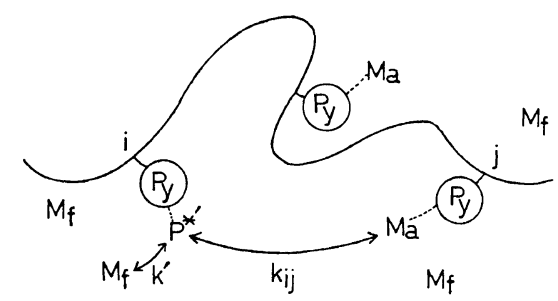

$B$

Figure 1. Representation of polymerization mechanism propagated by activated monomers: (A), initiation by $\alpha$-picoline; (B), initiation by poly(2-vinylpyridine).

NCA mechanism. ${ }^{10,24}$ The reaction mechanism can be represented as drawn in Figure 1. In Figure 1A only the intermolecular reaction of activated NCA $\left(\mathrm{P}^{*}\right)$ which is bound to $\alpha$-picoline by ion-pairing with free NCA $(\mathrm{M})$ is considered. In Figure $1 \mathrm{~B}$ both the intermolecular reaction of activated $\mathrm{NCA}\left(\mathrm{P}^{* \prime}\right)$ which is bound to poly(2-VP) by ion-pairing with free NCA $\left(\mathrm{M}_{\mathrm{f}}\right)$, and the intramolecular reaction of $\mathrm{P}^{* \prime}$ with bound NCA $\left(\mathrm{M}_{\mathrm{a}}\right)$ are considered.

According to the above scheme, $R_{\mathrm{p}}{ }^{7}$ and $R_{\mathrm{p}}{ }^{25}$ should be given by eq 1 and 2 , respectively. In eq 2, $N$ and [A] represent the degree of polymerization of poly(2-VP) and the total concentration of the pyridyl group, respectively,

$$
\begin{gathered}
R_{\mathrm{p}}=k\left[\mathrm{P}^{*}\right][\mathrm{M}] \\
R_{\mathrm{p}}{ }^{\prime}=k^{\prime}\left[\mathrm{P}^{* \prime}\right]\left[\mathrm{M}_{\mathrm{f}}\right]+\sum_{i, j=1}^{N} k_{i j}\left[\mathrm{P}^{* \prime}\right]\left[\mathrm{M}_{\mathrm{a}}\right] / N[\mathrm{~A}]
\end{gathered}
$$

and these were kept constant in the present investigation. Therefore, the relative rate of polymerization by poly(2-VP) against that by $\alpha$-picoline is given by eq 3 , where $\alpha$ and $\beta$ represent the fractions of NCA activated by $\alpha$ picoline and poly(2-VP), respectively.

$$
\frac{R_{\mathrm{p}}{ }^{\prime}}{R_{\mathrm{p}}}=\frac{k^{\prime}}{k} \frac{\beta}{\alpha}+\frac{\sum_{i, j=1}^{N} k_{i j} / N[\mathrm{~A}]-k^{\prime}}{k} \frac{\beta}{\alpha} \frac{\left[\mathrm{M}_{\mathrm{a}}\right]}{[\mathrm{M}]}
$$

The solvent and ring-substituent of NCA will affect the activation of NCA $(\alpha$ and $\beta)$ and the elementary reactions $\left(k, k^{\prime}\right.$, and $\left.k_{i j}\right)$. However, it is expected that the influence will be cancelled in the terms with $\beta / \alpha, k^{\prime} / k$, and $k_{i j} / k$. A solvent-dependent conformation of poly(2-VP) may affect the reactivity of the polymer in solution.
However, this has been the case only for the reactions catalyzed by a polymer in a specific solvent composition such as a theta solvent. ${ }^{26-28}$ Arichi, et al. ${ }^{29}$ measured the viscosity and the osmotic pressure of a fraction of poly (2-VP) in various solvents, and determined the parameters for the solubility of poly(2-VP). On the basis of these parameters they proposed that the solubility parameter $\delta$ of poly(2-VP) was 10.4 (cal/ $\mathrm{m} l)^{1 / 2}$. In the same paper ${ }^{29}$, they mentioned $\delta$ 's of nitrobenzene and DMF as 10.0 and 11.8, respectively; these values are not very different from 10.4 of poly(2-VP), suggesting that nitrobenzene and DMF are good solvents for poly(2-VP). In another paper $\mathrm{Arichi}^{30}$ reported the intrinsic viscosity-molecular weight relationship of poly$(2-\mathrm{VP})$ in various solvents at $25.0^{\circ} \mathrm{C}$ : the relationship in DMF was $[\eta]=1.47 \times 10^{-4} M_{w}{ }^{0.67}$. The $\alpha$ value (0.67) indicates that DMF is a good solvent for poly(2-VP). We prepared atactic poly(2-VP) with the molecular weight of 47,600 by a radical mechanism, and determined the intrinsic viscosity of the poly(2-VP) in the solvents partinent to the present investigation. $[\eta]$ at $25^{\circ} \mathrm{C}$ was 0.19 in nitrobenzene, 0.20 in DMF, 0.21 in acetophenone, and 0.22 in methyl benzoate. These values suggest that poly $(2-\mathrm{VP})$ is equally soluble in the four solvents. Since the solvents used in the present investigation have been shown to be equally good solvents for poly(2VP), it is hard to explain the effect of solvent on $R_{\mathrm{p}}{ }^{\prime} / R_{\mathrm{p}}$ in terms of different conformations of poly (2-VP). Consequently, the effects of solvent and ring-substituent of NCA must appear in $R_{\mathrm{p}}{ }^{\prime} / R_{\mathrm{p}}$ most strongly through the change of $\left[\mathrm{M}_{\mathrm{a}}\right] /$ $[\mathrm{M}]$. On the basis of this consideration, the experimental results will be discussed below. 
NCA Polymerization by Polymer

Table VII. Comparison of the polymerization rate by poly(2-vinylpyridine) $\left(R_{\mathrm{p}}{ }^{\prime}\right)$ with that by $\alpha$-picoline $\left(\boldsymbol{R}_{\mathrm{p}}\right)$ in various solvents

\begin{tabular}{|c|c|c|c|c|}
\hline & Dimethylformamide & Nitrobenzene & Methyl benzoate & Acetophenone ${ }^{b}$ \\
\hline$p-\mathrm{NO}_{2} \mathrm{Phe} \mathrm{NCA}$ & $0.27-0.42$ & & & 1.56 \\
\hline$m-\mathrm{NO}_{2} \mathrm{Ph}$ NCA & $0.31-0.46$ & $1.09-1.44$ & $2.66-4.15$ & 3.16 \\
\hline Phe NCA & 0.28 & $1.17-2.03$ & 2.46 & 3.11 \\
\hline$p-\mathrm{CH}_{3} \mathrm{OPhe} \mathrm{NCA}$ & 0.38 & $1.69-1.87$ & 1.47 & 1.70 \\
\hline
\end{tabular}

a Compared in terms of $R_{\mathrm{p}}{ }^{\prime} / R_{\mathrm{p}}$ ratio; [NCA], $0.1 M$; [NCA]/[Pyridine], $1 ; 35^{\circ} \mathrm{C}$.

${ }^{\mathrm{b}}$ [NCA]/[Pyridine], 0.2 .

For the discussion of the experimental results, $R_{\mathrm{p}}{ }^{\prime} / R_{\mathrm{p}}$ values are summarized in Table VII. $\alpha$ Picoline $\left(\mathrm{p} K_{\mathrm{a}}=5.97^{31}\right)$ is a stronger base and should activate NCA more strongly than poly $(2-\mathrm{VP})^{32}$ $\left(\mathrm{p} K_{\mathrm{a}}=3.34^{33}\right)$, indicating $\alpha>\beta$. If no specific interaction exists between the initiator and the NCA, $R_{\mathrm{p}}$ should be larger than $R_{\mathrm{p}}{ }^{\prime}$ because $\left[\mathrm{M}_{\mathrm{a}}\right]=0$ in this condition. In DMF, $R_{\mathrm{p}}{ }^{\prime} / R_{\mathrm{p}}$ was nearly 0.3 and independent of the ring substituent of NCA. This proves that no specific interaction exists between NCA molecules and poly(2-VP) in DMF. ${ }^{8,9}$ The constancy of $R_{\mathrm{p}}{ }^{\prime} / R_{\mathrm{p}}$ for different ring substituents of NCA validates the treatment leading to eq 3 .

In nitrobenzene, less basic poly(2-VP) induced a faster polymerization than more basic $\alpha$-picoline, and the $R_{\mathrm{p}}{ }^{\prime} / R_{\mathrm{p}}$ value was nearly 1.5 . In this solvent a hydrogen bond is formed between NCA and poly(2-VP). Since intramolecular collisions between $\mathrm{P}^{*}$ and $\mathrm{M}_{\mathrm{a}}$ along a flexible chain of poly(2-VP) take place frequently, $R_{\mathrm{p}}{ }^{\prime} / R_{\mathrm{p}}$ becomes larger than unity. ${ }^{7}$ In this solvent too, $R_{\mathrm{p}}{ }^{\prime} / R_{\mathrm{p}}$ was not affected by the ring substituent of NCA. This fact implies that the hydrogen bonding is not influenced by the ring substituent of NCA. Such a view is substantiated by the experimental data shown in Tables I and II. With poly(Sar)DMA, which binds NCA molecules by hydrogen bonding and initiates the polymerization, the acceleration of polymerization and the adsorption of NCA are not particularly correlated with the nature of the ring substituent of Phe NCA's.

In methyl benzoate and acetophenone, $R_{\mathrm{p}}{ }^{\prime} / R_{\mathrm{p}}$ was not only larger than unity, but was also susceptible to the nature of ring substituent of NCA. In these solvents a hydrogen bond is formed between NCA molecules and poly $(2-\mathrm{VP}),{ }^{9}$ so that $R_{\mathrm{p}}{ }^{\prime} / R_{\mathrm{p}}$ becomes larger than unity. In addition to this, another interaction which would be variable with the ring substituent of NCA should operate. Since $R_{\mathrm{p}}{ }^{\prime} / R_{\mathrm{p}}$ increased as the electron-accepting property of the ring substituent was enhanced, it is feasible to consider a chargetransfer interaction as the additional effect. ${ }^{9}$ Taking Phe NCA as the standard, an electronaccepting $m-\mathrm{NO}_{2} \mathrm{Phe} \mathrm{NCA}$ interacts more effectively with an electron-donating poly(2-VP) to increase $\left[\mathrm{M}_{\mathrm{a}}\right]$ and hence $R_{\mathrm{p}}{ }^{\prime} / R_{\mathrm{p}}$, whereas an electron-donating $p-\mathrm{CH}_{3} \mathrm{OPhe} \mathrm{NCA}$ interacts less effectively with poly $(2-\mathrm{VP})$ to decrease $\left[\mathrm{M}_{\mathrm{a}}\right]$ and hence $R_{\mathrm{p}}{ }^{\prime} / R_{\mathrm{p}}$. In Table VI the difficulty which $p-\mathrm{CH}_{3} \mathrm{OPhe} \mathrm{NCA}$ has in forming a hydrogen bond with poly (2-VP) is clearly shown. These experimental results confirm that the chargetransfer interaction affects $\left[\mathrm{M}_{\mathrm{a}}\right]$ and consequently $R_{\mathrm{p}}{ }^{\prime} / R_{\mathrm{p}}$. The charge-transfer interaction might affect the transition state of the intramolecular reaction along the polymer chain, and thus change $R_{\mathrm{p}}{ }^{\prime} / R_{\mathrm{p}}$. However, an apparent correspondence of the experimental results between Tables V and VI suggests that the former explanation is more plausible.

For $p-\mathrm{NO}_{2} \mathrm{Phe} \mathrm{NCA}$, which possesses a strongly electron-accepting group, $R_{\mathrm{p}}{ }^{\prime} / R_{\mathrm{p}}$ in acetophenone was smaller than expected. $p-\mathrm{NO}_{2} \mathrm{Phe} \mathrm{NCA}$ is very crystalline and is not easily soluble in acetophenone at the concentration of $0.1 \mathrm{M}$ at $35^{\circ} \mathrm{C}$. This could be one reason for the small $R_{\mathrm{p}}{ }^{\prime} / R_{\mathrm{p}}$.

The present investigation has revealed that the coupled hydrogen bonding and chargetransfer interaction between polymer initiator and NCA can yield a selectivity in the polymerization with a suitable choice of solvent. On this basis, the control of the chemical reaction by a polymer catalyst (enzyme model), which has a refined selectivity toward a substrate, will be developed. 


\section{REFERENCES}

1. M. L. Bender, "Mechanisms of Homogeneous Catalysis from Protons to Proteins," John Wiley \& Sons, Inc., New York, N.Y., 1971.

2. W. P. Jencks, "Catalysis in Chemistry and Enzymology," McGraw-Hill, Inc., New York, N.Y., 1969.

3. K. Narita, Y. Imanishi, and F. Sakiyama, "Enzymes and Polymer Catalysts," Kagaku Dojin, Kyoto, 1972.

4. M. Sisido, Y. Imanishi, and S. Okamura, Biopolymers, 7, 937 (1969).

5. M. Sisido, Y. Imanishi, and S. Okamura, Polymer J., 1, 198 (1970).

6. Y. Imanishi, K. Sueda, and T. Higashimura, Kobunshi Kagaku (Chem. High Polymers), 30, 61 (1973).

7. Y. Imanishi, S. Nagaoka, K. Suzuoki, and T. Higashimura, Biopolymers, 12, 181 (1973).

8. K. Suzuoki, Y. Imanishi, T. Higashimura, and S. Okamura, ibid., 7, 917 (1969).

9. K. Suzuoki, Y. Imanishi, T. Higashimura, and S. Okamura, ibid., 7, 925 (1969).

10. M. Szwarc, Adv. Polym. Sci., 4, 1 (1965).

11. G. H. Cleland, J. Org. Chem., 34, 744 (1969).

12. S. Arichi, S. Mitsuya, N. Sakamoto, and H. Murata, Bull. Chem. Soc. Japan, 39, 428 (1966).

13. G. Geuskens, J. C. Lubikulu, and C. David, Polymer, 7, 63 (1966).

14. G. Weill and G. Hermann, J. Polym. Sci., Part A-2, 5, 1293 (1967).

15. K. Matsuzaki and T. Sugimoto, ibid., A-2, 5, 1320 (1967).

16. F. L. Hahn and M. Loos, Ber., 51, 1442 (1918).
17. A. Patchornik and Y. Shalitin, Anal. Chem., 33, 1887 (1961).

18. C. H. Bamford and R. C. Price, Trans. Faraday Soc., 61, 2208 (1965).

19. D. G. H. Ballard and C. H. Bamford, Proc. Roy. Soc., Ser. A, 236, 384 (1956).

20. E. M. Arnett, Progr. Phys. Org. Chem., 1, 223 (1963).

21. J. V. Hatton and W. G. Schneider, Can. J. Chem., 40, 1285 (1962).

22. M. Tamres, S. Searles, E. M. Leighty, and D. M. Mohrman, J. Amer. Chem. Soc., 76, 3983 (1954).

23. Y. Imanishi, A. Yoshii, and T. Higashimura, unpublished results.

24. C. H. Bamford and H. Block, "Polyamino Acids, Polypeptides, and Proteins," M. A. Stahmann, Ed., The University of Wisconsin Press, Madison, Wisconsin, 1962, p 65.

25. Y. Imanishi, S. Nagaoka, and T. Higashimura, Polymer J., 4, 644 (1973).

26. V.S. Pshezetsky, I. Massouh, and V. A. Kabanov, J. Polym. Sci., Part C, No. 22, 309 (1968).

27. C. G. Overberger and M. Morimoto, J. Amer. Chem. Soc., 93, 3222 (1971).

28. C. G. Overberger and C. J. Podsiadly, Bioorg. Chem., 3, 16 (1974).

29. S. Arichi, H. Matsuura, Y. Tanimoto, and H. Murata, Bull. Chem. Soc. Japan, 39, 434 (1966).

30. S. Arichi, ibid., 39, 439 (1966).

31. H. C. Brown and X. R. Mihm, J. Amer. Chem. Soc., 78, 1723 (1956).

32. C. H. Bamford and H. Block, J. Chem. Soc., 4989 (1961).

33. T. Kitajima, Thesis, Kyoto University, 1970. 